\title{
Article \\ Position-Specific Attentional Skills in Team Sports: A Comparison between Defensive and Offensive Football Players
}

\author{
Stefanie Klatt ${ }^{1,2, *(1)}$ and Josef Nerb ${ }^{3}$ \\ 1 Institute of Exercise Training and Sport Informatics, German Sport University Cologne, \\ 50933 Cologne, Germany \\ 2 School of Sport and Health Sciences, University of Brighton, Eastbourne BN20 7SR, UK \\ 3 Institute of Psychology, University of Education, 79117 Freiburg, Germany; nerb@ph-freiburg.de \\ * Correspondence: s.klatt@dshs-koeln.de; Tel.: +49-221-4982-4312
}

Citation: Klatt, S.; Nerb, J.

Position-Specific Attentional Skills in Team Sports: A Comparison between Defensive and Offensive Football Players. Appl. Sci. 2021, 11, 5896. https://doi.org/10.3390/app11135896

Academic Editor: Mark King

Received: 11 June 2021

Accepted: 23 June 2021

Published: 25 June 2021

Publisher's Note: MDPI stays neutral with regard to jurisdictional claims in published maps and institutional affiliations.

Copyright: (c) 2021 by the authors. Licensee MDPI, Basel, Switzerland This article is an open access article distributed under the terms and conditions of the Creative Commons Attribution (CC BY) license (https:// creativecommons.org/licenses/by/ $4.0 /)$
Featured Application: For the first time, we were able to show that the players not only differ in the conscious perception of unexpected objects that are irrelevant to the sport as a function of their playing position, but also vary when the perception of the unexpected relevant object is useful for finding tactical solutions in a given game situation. This is not only interesting for scientific enquiry, but also for coaches who could take these findings into account when assigning specific playing positions within their team.

Abstract: Over the last few decades, technical as well as cognitive skills and their relation to positionspecific skill requirements have been extensively investigated as indicators for players' performance in team sports. To explore the impact of positioning in football on inattentional blindness we employed dynamic tasks that presented an unexpected object and analyzed its noticing rates in three different experiments. In Experiment 1, amateur and expert football players performed a well-established inattentional blindness task of counting the number of times a basketball was passed between two groups while an unexpected, non-sport specific object was introduced to the situation. Noticing rates were higher for strikers compared to players of other playing positions. The findings support a position-specific advantage regarding inattentional blindness for more offensive players compared to more defensive players. Using the same inattentional blindness task, this finding was investigated in Experiment 2 in more detail, i.e., by differentiating between more playing positions. Results revealed that offensive players (in particular strikers) observed unexpected objects more frequently than defensive players. Experiment 3 used a newly developed football-specific task requiring participants to find solutions in different game situations with an unexpected free-standing player appearing in one of these situations. Defensive players again showed more inattentional blindness than offensive players (in particular offensive mid-fielders), i.e., offensive players perceived the unmarked player more often. This indicates that players not only differ in the conscious perception of unexpected objects that are irrelevant to the sport as a function of their playing position, but also show differences when the perception of the unexpected relevant object is useful for finding tactical solutions in a given game situation. Our findings provide further insight into the importance of the definition of position-specific skill requirements in team sports.

Keywords: inattentional blindness; expertise; perception; football

\section{Introduction}

When people focus their attention on something, they often fail to notice unexpected occurrences, even if they happen right in front of them. This phenomenon is known as inattentional blindness [1] and has been shown to be a highly robust finding in psychology [2,3]. Over the last few years, a number of studies have applied inattentional blindness paradigms in the field of decision making in sports [4]. Some of these studies have found 
differences in inattentional blindness between expert team sport athletes and novices. For example, one study showed that expert basketball players detect an unexpected object in a basketball task more often than amateur players do [5].

As team sport players are usually exposed to a whole range of different environmental influences and various stimuli that they have to perceive on the playing field, it is hardly surprising that single pieces of information are sometimes overlooked when the attentional focus is on other stimuli in that moment. This can be explained by the fact that humans have a limited information-processing capacity, and consequently, it is important to primarily focus on the most task-relevant or situation-relevant information for the most optimum outcome [6,7]. In team sports, this mostly refers to the teammates and opponents as well as the ball. However, situations occur in which players, who are unexpectedly unmarked, are not involved in offensive game situations by their teammates [8]. Two previous studies have shown, for example, that participants watching short videos of basketball or handball plays, often fail to notice an open player, even while deciding who should receive the next pass from the player holding the ball [4,9]. The oversight of open teammates and opponents can depend on many factors, one of which is the players' positioning on the pitch. When we look at the different positions of players on the pitch individually, for example in football, it becomes apparent that teammates and opponents are usually all placed on the pitch in front of a goalkeeper in football. On the other hand, strikers often receive passes from behind the optimum position for scoring, while running up to the opponents' goal and while teammates and opponents may be positioned to their left, right, behind them, and in front of them.

Various on-field and analytical studies have dealt with position-specific skills and specializations in team sports. Skill requirements vary from position to position and it is well-known that certain positions require specific traits [10]. In football, for example, center midfielders (attacking and defensive) have to pick up and process information from multiple sources (e.g., players in front, behind, and next to them) [10,11]. As they spend most of the playing time in the central parts of the field, it is necessary for them to absorb information from all around them (a 360-degree visual input) to be able to make the best decision possible and achieve optimal performance [12]. This distinguishes them from other players on other positions, such as the goalkeeper's position.

So far, it has remained uncertain whether different playing positions in sports (e.g., the goalkeeper compared to offensive players in handball or football, or the quarterback compared to the running back or center in American football) correspond to differences in performance in detecting unexpected objects, unmarked players, or suddenly appearing opponents, due to their different range of tasks and perceptions on the pitch. In three various independent experiments, this hitherto overlooked factor of a possible positionspecific inattentional blindness was investigated in football players. We assumed that the strikers would detect an unexpected object (an object being not important for the decision-making task in Experiments 1 and 2, but being important for the sport-specific decision making in Experiment 3) more often compared to the other players. Furthermore, in Experiment 1, it was tested whether position-specific inattentional blindness can be relevant for amateurs as well as experts in case of football. Based on previous research findings on group differences [5], it was expected that experts would be less susceptible than amateur players to inattentional blindness.

\section{Experiment 1}

Experiment 1 was conducted to investigate the above defined research question whether strikers notify an unexpected object more often than players of other playing positions do and also to investigate any expertise level differences. 


\subsection{Method}

\subsubsection{Participants}

A statistical power analysis was performed to estimate the necessary sample size (G*Power 3.1.9.7, Düsseldorf, Germany). With a power of 0.80 and an alpha of 0.05 , the projected sample size needed for medium effects of $w=0.40$ was at least $N=50$. However, due to an anticipated high drop-out rate due to the level of awareness of the used video, we decided to request approximately twice as many participants as calculated with G*Power. Therefore, a total of 93 male subjects, aged 18 to 38 years ( $M_{\text {age }}=24.8$ years, $S D=4.5$ years) participated in Experiment 1. Players were regarded as amateurs $\left(n=50, M_{\text {age }}=25.3\right.$ years, $S D=4.8$ years) who played in the 9th and 10th division of the German football league at the time of data collection. The experts ( $n=43, M_{\text {age }}=24.3$ years, $S D=4.0$ years) participating in Experiment 1, played in the 5th and 6th division of the German football league. Overall, 26 of the subjects reported playing the offense, usually as a striker; all other subjects usually played as goalkeepers $(n=7)$, defenders $(n=29)$, or midfielders $(n=31)$.

Participants were excluded from analysis ( 24 amateur and 18 expert players) in two conditions: if they indicated in the follow-up questionnaire that they had anticipated the unexpected object because of previous knowledge of inattentional blindness or related research; or if they failed to notice the unexpected object in the control condition where they did not have to perform the primary task (full-attention trial). Consequently, only the data of 61 participants ( 35 experts, $M_{\text {age }}=24.6$ years, $S D=4.0$ years, 26 amateurs, $M_{\text {age }}=24.9$ years, $S D=4.5$ years) was included in the analysis.

All participants reported normal or corrected-to-normal vision (with either glasses or contact lenses) and were not involved in any sensorimotor research within the preceding six months. The study was approved by the local University ethics board (number 094/21). Written consent was obtained from all participants prior to testing according to the Declaration of Helsinki, 1975.

\subsubsection{Materials and Procedure}

Participants were tested individually in a laboratory. Each testing session lasted approximately $10 \mathrm{~min}$. Figure 1 shows a flow chart presenting the experiment procedure. Each participant watched a short video clip by Simons and Chabris [3] (https:/ /youtu. be/vJG698U2Mvo; www.theinvisiblegorilla.com/gorilla_experiment.html; accessed date: 14 July 2020). The video showed two teams of three players each, one team wearing white shirts and the other wearing black shirts. The members of each team passed an orange basketball to each other, using both bounce and aerial passes. While passing the ball, the players moved around in front of a background showing three elevator doors. A seventh person, dressed in a gorilla costume appeared midway through the video, walking through the scene and was visible for about ten seconds. In the center of the scene, the gorilla turned to face the camera. As the participants were not forewarned about the gorilla, its appearance was unexpected for them. The participants were asked to count the number of times the players wearing the white shirts passed the ball to one of their team members (total of 15 passes). After viewing the video, the participants noted down the number of passes which they counted, on a white sheet of paper.

Following the procedure of Simons and Chabris [3], participants were asked to provide answers to a series of additional questions: (I) While you were doing the counting, did you notice anything unusual on the video? (II) Did you notice anything other than the six players? (III) Did you see anyone else (besides the six players) appear on the video? (IV) Did you see a gorilla walk across the screen? If any of the questions were answered with "yes" the experimenter asked for more details. If at any point the participant mentioned the gorilla, the remaining questions were skipped. Furthermore, the participants were asked whether they had ever participated in a similar experiment or had heard of such an experiment or the general phenomenon of inattentional blindness. Finally, the participants were debriefed by replaying the video. 


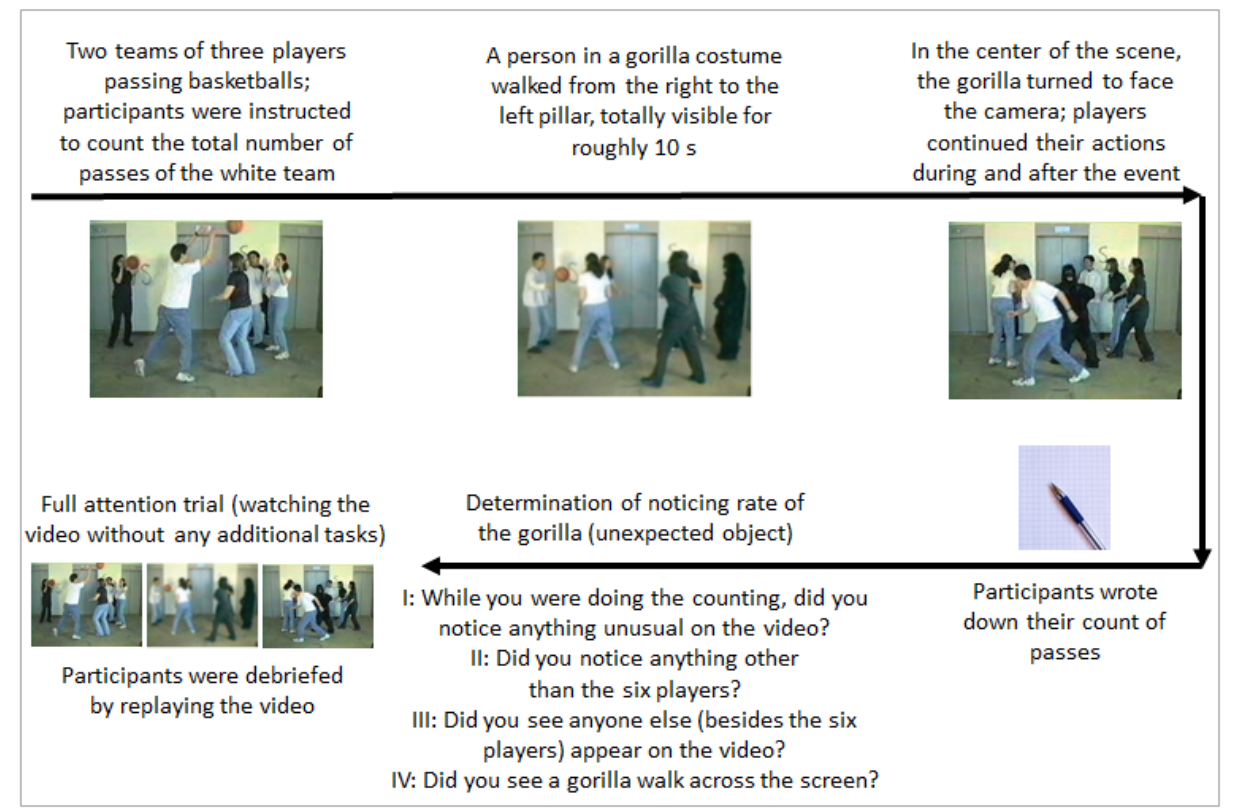

Figure 1. A flow chart demonstrating the procedure of Experiments 1 and 2.

\subsubsection{Data Analysis}

Separate chi-square tests were used to investigate whether participants' playing positions (strikers vs. other positions) as well as participants' expertise level (amateurs vs. experts) influenced the noticing rates of the unexpected stimulus. In the study of Simons and Chabris [3] the results of the four questions that were asked after the presentation of the video were aggregated. However, as in our study the participants' responses were always consistent across the four questions, we reported overall rates of noticing. As a consequence, the outcome variable was dichotomous (unexpected object noticed vs. not); hence, the $\chi^{2}$-tests were used. In addition to chi-square tests, odds ratios (OR) with $95 \%$ confidence intervals $(\mathrm{CI})$ are reported as standardized measures of effect size. The significance level was set to $\alpha=0.05$.

\subsection{Results}

In total, 45 participants reported seeing the gorilla (noticers, $74 \%$ ) and 16 reported not seeing the gorilla (non-noticers, $26 \%$; Table 1). Furthermore, the results showed a significant relationship between the players' playing position and their likelihood of showing inattentional blindness: strikers saw the gorilla more often than the players on other positions $(94 \%$ vs. $66 \%), \chi^{2}(1)=5.04, p=0.025, \mathrm{OR}=8.3,95 \% \mathrm{CI}[1.0,68.6]$.

Table 1. Rates of noticing the unexpected object (absolute frequency) per group.

\begin{tabular}{lcc}
\hline & $\begin{array}{c}\text { Unexpected Object Noticed } \\
\text { (Absolute Frequency) }\end{array}$ & $\begin{array}{c}\text { Unexpected Object Unnoticed } \\
\text { (Absolute Frequency) }\end{array}$ \\
\hline Strikers & 16 & 1 \\
Other players & 29 & 15 \\
Expert players & 27 & 8 \\
Amateur players & 18 & 8 \\
\hline
\end{tabular}

No significant difference was discernible between the two groups (amateurs, experts) of football players with regard to the incidence of inattentional blindness, $\chi^{2}(1)=0.48$, $p=0.487, \mathrm{OR}=1.5,95 \% \mathrm{CI}[0.5,4.7]$. 


\subsection{Discussion}

The results showed that both experts and amateurs detected the gorilla in the video with equal frequency. However, strikers in football clearly showed less inattentional blindness on the pitch, compared to players who usually play on other positions (e.g., goalkeepers, defenders, midfielders). This finding can possibly be explained by the fact that a striker has to operate under continuous pressure from opponents, among other reasonings. On the other playing positions in football, e.g., in the defense, players often have more time for their decisions because they are further away from the opponent's goal, and thus, they are not as closely marked by the opponents as they would be in the penalty area. However, while Experiment 1 only distinguished between strikers and other playing positions, it did not clarify whether the conscious awareness of unexpected objects also differs among other positions such as between goalkeepers and midfielders. This question was addressed in Experiment 2.

\section{Experiment 2}

Experiment 1 revealed differences in inattentional blindness for football players as a function of their playing position on the pitch which made the strikers see the unexpected object more often than players who usually play on other positions. However, while the players in Experiment 1 were only grouped into strikers and other players, Experiment 2 was designed to explore the inattentional blindness differences between football players in more detail. In Experiment 2, no distinction was made between expert and amateur players and only one homogenous sample with nearly the same level of expertise was investigated in order to increase the number of individual positional groups (e.g., strikers, midfielders, defenders, goalkeepers). We assumed that the more offensive a player's playing position is, the less pronounced his inattentional blindness would be.

\subsection{Method}

A statistical power analysis was performed to estimate the necessary sample size (G*Power 3.1.9.7, Germany). With a power of 0.80 and an alpha of 0.05 , the projected sample size needed for medium effects of $w=0.40$ including four groups (goalkeepers, defenders, midfielders, strikers) was at least $N=69$. Due to a high anticipated drop out because of the video's reputation, a significantly greater sample size was recruited. Eligibility criteria for including a participant to the final sample were ignorance of the general phenomenon of sustained inattentional blindness and similar experiments. One hundred male subjects aged 18 to 38 years $\left(M_{\text {age }}=24.2\right.$ years, $S D=4.4$ years) participated under the same ethical and health conditions as in Experiment 1. Data from twelve subjects was excluded because they did not notice the unexpected object in the full-attention trial. Consequently, only the data of 89 participants $\left(M_{\text {age }}=23.6\right.$ years, $S D=3.8$ years $)$ was included in the analysis. All of them played in the 7th, 8th, or 9th division of the German football league. Overall, 10 subjects reported their usual playing position as the goalkeeper, 26 played in the defense (defenders), 30 in the midfield (midfielders), and 23 in the offense (strikers). The design and procedure of Experiment 2 was identical to that of Experiment 1 (Figure 1): Participants watched again the 30-seconds video clip by Simons and Chabris [3] and was asked to count the number of passes of the white team. After watching the video, they were again required to provide answers to the same four questions as in Experiment: (I) While you were doing the counting, did you notice anything unusual on the video? (II) Did you notice anything other than the six players? (III) Did you see anyone else (besides the six players) appear on the video? (IV) Did you see a gorilla walk across the screen? If any of the questions were answered with "yes" the experimenter asked for more details. If at any point the participant mentioned the gorilla, the remaining questions were skipped.

\subsection{Data Analysis}

Separate chi-square tests were used to investigate whether participants' playing positions (goalkeepers, midfielders, defenders, strikers) influenced the noticing rates of 
the unexpected stimulus. As the participants' responses were again always consistent across the four questions, we reported overall rates of noticing. As a consequence, the outcome variable was dichotomous (unexpected object noticed vs. not); hence, the $\chi^{2}$-tests were used. In addition to chi-square tests, ORs with 95\% CIs are reported as standardized measures of effect size. The significance level was again set to $\alpha=0.05$.

\subsection{Results and Discussion}

In total, 65 participants reported seeing the gorilla (noticers, 73\%) and 24 reported not seeing the gorilla (non-noticers, 27\%; Table 2). There was a significant relationship between players' playing position and their likelihood of showing inattentional blindness, $\chi^{2}(3)=9.01, p=0.029$. Post-hoc pairwise comparisons indicated that the detection rate only differed significantly between the defenders and the strikers, $\chi^{2}(1)=8.39, p=0.004$, OR $=9.0,95 \%$ CI $[1.7,46.5]$. The defenders (54\%) saw the unexpected object less often than strikers (91\%). There was no significant difference in the detection rate among all other group comparisons: goalkeepers vs. midfielders, $\chi^{2}(1)=0.18, p=0.673, \mathrm{OR}=1.4$, $95 \%$ CI $[0.3,6.9]$; goalkeepers vs. defenders, $\chi^{2}(1)=0.78, p=0.379$, OR $=0.5,95 \% \mathrm{CI}$ $[0.1,2.4]$; goalkeepers vs. strikers, $\chi^{2}(1)=2.46, p=0.117, \mathrm{OR}=4.5,95 \%$ CI [0.6, 32.7]; defenders vs. midfielders, $\chi^{2}(1)=3.24, p=0.072, \mathrm{OR}=2.8,95 \%$ CI $[0.9,8.8]$; midfielders vs. strikers, $\chi^{2}(1)=1.98, p=0.160, \mathrm{OR}=3.2,95 \%$ CI $[0.6,17.1]$ (Bonferroni-corrected post-hoc comparisons had an adjusted alpha of 0.013 ).

Table 2. Rates of noticing the unexpected object (absolute frequency) per group.

\begin{tabular}{lcc}
\hline & $\begin{array}{c}\text { Unexpected Object Noticed } \\
\text { (Absolute Frequency) }\end{array}$ & $\begin{array}{c}\text { Unexpected Object Unnoticed } \\
\text { (Absolute Frequency) }\end{array}$ \\
\hline Goalkeepers & 7 & 3 \\
Midfielders & 14 & 12 \\
Defenders & 23 & 7 \\
Strikers & 21 & 2 \\
\hline
\end{tabular}

Our expectation, that inattentional blindness would be less pronounced in the players in more offensive playing positions, could only be partially confirmed by the statistical analyses. The strikers showed less inattentional blindness than the defenders. It was initially surprising that we did not find differences in the detection rate of the unexpected object between the other player groups. However, this finding may be explained by looking at the visual demands of the various playing positions. While no teammates or opponents are usually positioned behind or right next to the goalkeepers, it is still crucial that they keep an eye on several players at the same time. Only then are they likely to anticipate, based on other players' movements and behaviors, from where and by whom will the ball be kicked towards the goal. The fact that no differences in the detection rate of midfielders and strikers were found, might be explained by similar behavioral patterns and tasks that they adopt depending on their team's formation.

\section{Experiment 3}

While Experiment 1 revealed inattentional blindness differences between the strikers and the players usually playing on other positions in football, Experiment 2 deconstructed these results in more detail and showed that strikers usually pay more attention than defenders to unexpected objects. However, as Furley et al. [4] already described in their study, in sports, it is not necessarily a disadvantage to not detect unexpected events, as long as they are not critical in determining the outcome of the match (for example, the gorilla in Experiments 1 and 2).

The findings of the current study bring into question the actual importance of the strikers' higher detection rates of the unexpected occurrence (in this case, the appearance of the gorilla) compared to the defenders. While on the one hand, the players' ability to detect unexpected objects can be positive in real-time play situations, on the other hand it can also 
be considered a negative since the players may consequently devote a part of their limited attentional capabilities to objects which do not add any value to the accomplishment of the required task (for example, the gorilla in Experiments 1 and 2 is not relevant for correctly completing the counting task). Thus, sport-specific and more valid tasks should be employed in which unmarked teammates or unexpected opponents are meant to be perceived, both being certainly important aspects that matter in the given game situation. Therefore, Experiment 3 was designed to address this issue.

\subsection{Method}

\subsubsection{Participants}

A statistical power analysis was performed to estimate the necessary sample size (G*Power 3.1.9.7, Germany). With a power of 0.80 and an alpha of 0.05 , the projected sample size needed for medium effects of $w=0.40$ including four groups (goalkeepers, defenders, midfielders, strikers) was at least $N=69$. In order to adjust for any drop outs, a significantly greater sample size was recruited. Ninety-five male subjects, aged 18 to 32 years $\left(M_{\text {age }}=22.7\right.$ years, $S D=3.6$ years $)$, participated under the same ethical and health conditions as in Experiments 1 and 2. Data from five additional subjects were excluded because they either did not notice the unexpected object in the full-attention trial $(n=1)$, or they did not recognize the running direction of the opposing player correctly $(n=4)$. All the participants played in the 5 th, 6 th, 7 th, 8th, or 9th division of the German football league. Overall, 12 subjects reported their usual playing position as the goalkeeper, 24 in the defense (defenders), 32 in the midfield (midfielders), and 27 in the offense (strikers).

\subsubsection{Materials and Procedure}

Participants were tested individually in a laboratory. Each participant watched a total of four different 11-s video clips. The video clips were generated by using the software 3-D Soccer Designer ${ }^{\circledR}$. Following the design of a previous study [4], each video showed a game situation in which a football team wearing red shirts played against a team with blue shirts. At the beginning of the video, a player was marked in red, and the participants were asked to put themselves in that player's position (Figure 2, upper graphic). At the end of the video, this player received the ball after his teammates had passed the ball back and forth and adopted different positions on the pitch. The final frame of the video froze and immediately switched to a white screen. The participants had two tasks ([4] for a similar design): one, they had to pay attention to the position of their direct opponent (marked with a yellow circle at the beginning of the video) and to identify whether this opponent had moved towards them or maintained his position during the video. Two, they were asked to make a tactical decision that would most likely lead to a goal for their team. In the fourth video, an unexpected, unmarked player entered the scene from the left side of the screen and positioned himself in the center, in front of the goal (Figure 2, lower graphic). Thus, passing the ball to this player presented the best tactical decision alternative. After every video, the participants wrote down the movement behavior of the direct opponent as well as the best tactical decision to continue the play. They were also asked if they had noticed anything unusual in the last video. If they answered this question with a "yes", they were to describe in detail what they had noticed; if they answered with "no" they should watch the video once again without the observation of the opponent player to check about the general perceptual capacity (full attention trial). After completing all trials, the participants were asked whether they had been familiar with this or any other related experiments prior to their participation. It was also checked whether they had noticed that they had been watching the same video on the critical trial and the full-attention trial, or not. Figure 3 shows a flow chart presenting the experiment procedure. 

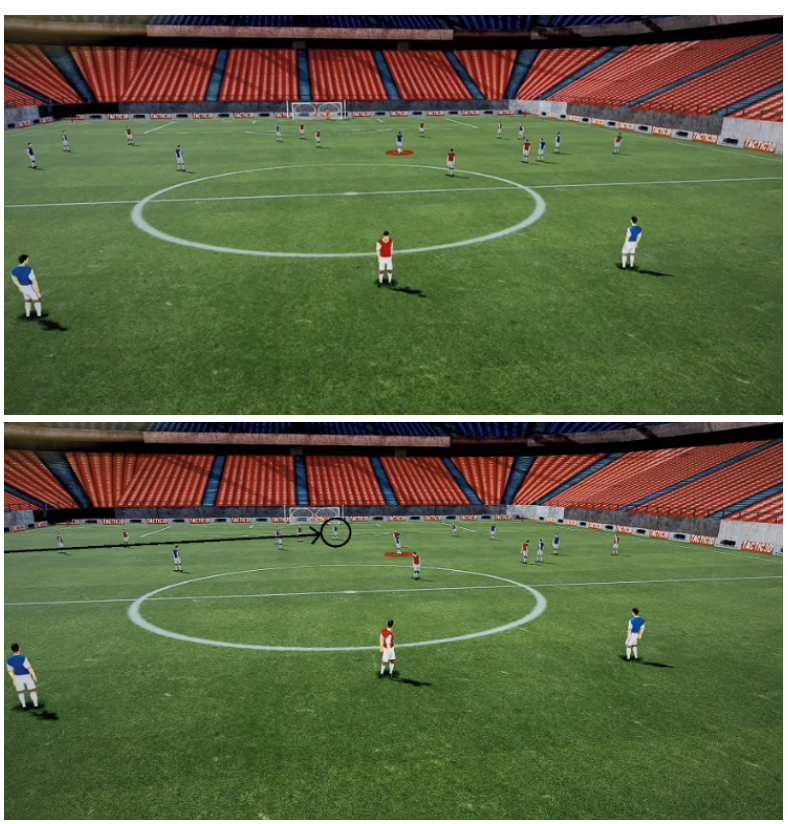

Figure 2. The figure on the top presents one example of the final frame of the three different game situations which were shown before the video scene with the unexpected teammate was introduced to the setting (figure on the bottom). The frames were shown before the screen turned white and the participants had to make a decision about how to continue the play in the best way possible. The participants were required to put themselves in the position of the player marked with the red circle and state, besides the best possible decision, whether their direct opponent had moved closer or maintained his position throughout the observed scene. In the last game situations, an unexpected, unmarked player entered the scene from the left side of the screen and positioned himself in the center, in front of the goal (bottom figure). Thus, passing the ball to this player presented the best tactical decision alternative. (Please note that the black circle around the unexpected, freestanding teammate and his running path (marked with an arrow) have been plotted exclusively for this figure and were not visible to the participants.)

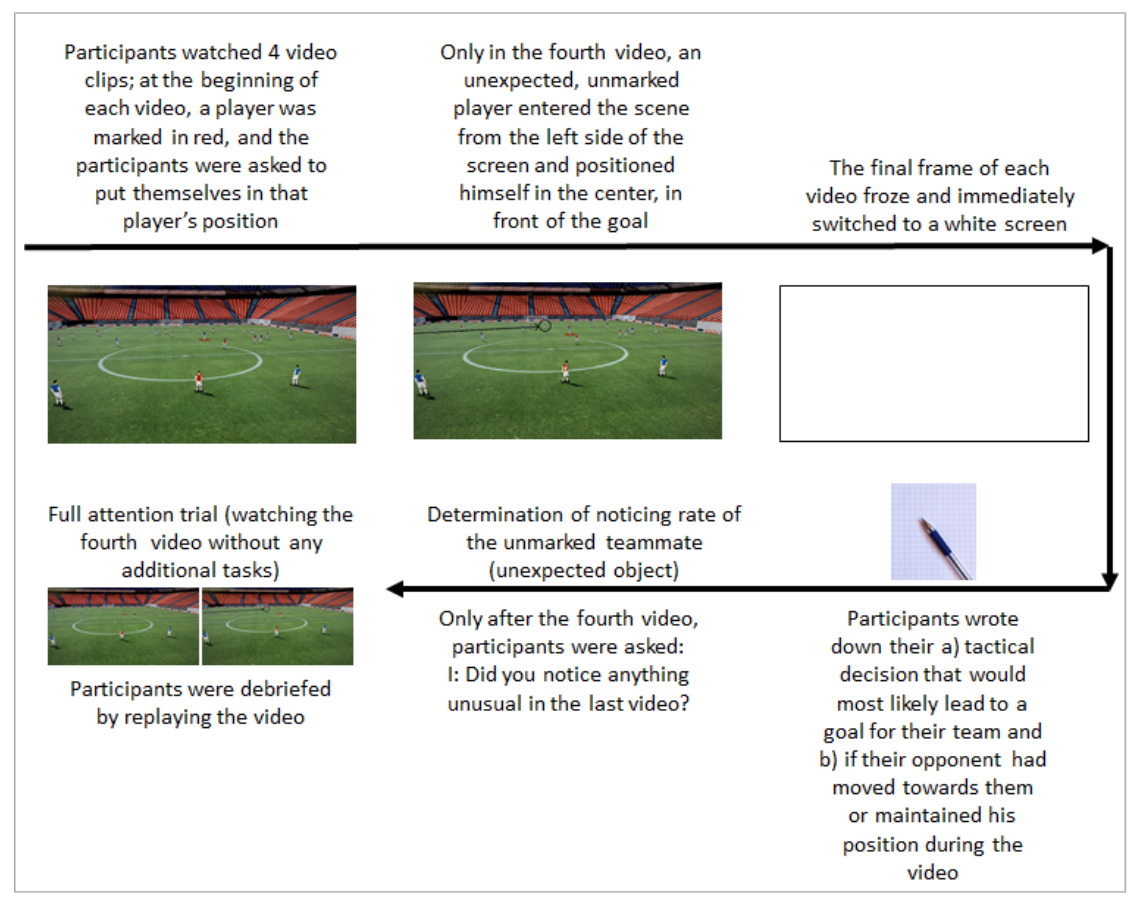

Figure 3. A flow chart demonstrating the procedure of Experiment 3. 


\subsubsection{Data Analysis}

Separate chi-square tests were used to investigate whether participants' playing positions (goalkeepers, midfielders, defenders, strikers) influenced the noticing rates of the unexpected stimulus. As the outcome variable was dichotomous (unexpected unmarked teammate noticed vs. not) the $\chi^{2}$-tests were used. In addition to chi-square tests, ORs with $95 \%$ CIs are reported as standardized measures of effect size. The significance level was again set to $\alpha=0.05$.

\subsection{Results and Discussion}

In total, 61 participants reported seeing the unexpected, unmarked teammate (noticers $64 \%$ ) and 34 reported not seeing him (non-noticers, $36 \%$ ). Thus, our results were slightly higher than those in a previous handball study [9] (44\% failed to notice the unguarded player). We found a significant relationship between the players' playing positions and their likelihood of showing inattentional blindness, $\chi^{2}(3)=10.02, p=0.018$. Post-hoc pairwise comparisons indicated that the detection rate differed significantly between the defenders and the midfielders, $\chi^{2}(1)=6.23, p=0.013$, OR $=4.2,95 \%$ CI $[1.3,13.5]$. The defenders ( $46 \%$ noticers) saw the unexpected object less often than the midfielders $(78 \%$ noticers; Table 3). There was no significant difference in the detection rate for all other group comparisons: goalkeepers vs. midfielders, $\chi^{2}(1)=5.35, p=0.021, \mathrm{OR}=5.0,95 \% \mathrm{CI}$ $[1.2,20.7]$; goalkeepers vs. defenders, $\chi^{2}(1)=0.06, p=0.813$, OR $=1.2,95 \% \mathrm{CI}[0.3,4.8]$; goalkeepers vs. strikers, $\chi^{2}(1)=3.79, p=0.052, \mathrm{OR}=4.0,95 \% \mathrm{CI}[1.0,16.8]$; midfielders vs. strikers, $\chi^{2}(1)=0.13, p=0.716, \mathrm{OR}=0.8,95 \% \mathrm{CI}[0.2,2.7]$; defenders vs. strikers, $\chi^{2}(1)=4.25$, $p=0.039, \mathrm{OR}=3.4,95 \% \mathrm{CI}[1.0,11.0]$ (Bonferroni-adjusted post-hoc comparisons had an adjusted alpha of 0.013 ).

Table 3. Rates of noticing the unexpected object (absolute frequency) per group.

\begin{tabular}{lcc}
\hline & $\begin{array}{c}\text { Unexpected Object Noticed } \\
\text { (Absolute Frequency) }\end{array}$ & $\begin{array}{c}\text { Unexpected Object Unnoticed } \\
\text { (Absolute Frequency) }\end{array}$ \\
\hline Goalkeepers & 5 & 7 \\
Midfielders & 25 & 7 \\
Defenders & 11 & 13 \\
Strikers & 20 & 7 \\
\hline
\end{tabular}

While Experiment 2 showed a difference in the inattentional blindness rate between the defenders and the strikers, in Experiment 3, we found a difference in the rate of inattentional blindness between the defenders and the midfielders. However, it should be noted that $22(69 \%)$ of the 32 midfielders reported being offensive midfielders and only 10 $(31 \%)$ reported being defensive midfielders. Therefore, we performed a further analysis comparing the group of all the defensive players (including all the goalkeepers, all the defenders, and the 10 defensive midfielders) with a group of all the offensive players (including the 22 offensive midfielders and all strikers). The group of the offensive players detected the unexpected player more often ( $86 \%$ noticers, $14 \%$ non-noticers) than the defensive players ( $41 \%$ noticers, $59 \%$ non-noticers), $\chi^{2}(1)=20.36, p<0.001$, OR $=8.5$, $95 \% \mathrm{CI}[3.2,23.0]$. It can, therefore, be concluded that our results replicate the findings in Experiment 1 and 2 in a more representative sport-specific situation that the defensive players show more inattentional blindness than the offensive players. While in Experiment 3 , a central offensive midfield player finally got the ball in front of the opposing defense line, future studies could use videos presenting game situations with more defensive situations in order to explore if the game situation itself does affect the players' inattentional blindness rate.

\section{General Discussion}

In three experiments, it was investigated whether the playing position of football players, as well as their football-specific expertise (Experiment 1), influence the likelihood 
to consciously perceive an unexpected stimulus when one's attention is engaged elsewhere. Amateur and expert players performed comparably well (Experiment 1). However, noticing rates were higher for offensive compared to defensive players both when using a well-established sport-unspecific task (Experiments $1 \& 2$ ) and a new football-specific inattentional blindness task (Experiment 3).

In Experiments 1 and 2, the phenomenon of inattentional blindness was examined in a basketball-specific test by Simons and Chabris [3]. The authors of the original study had reported a noticing rate of the unexpected event of $54 \%$ across all participants, while $46 \%$ failed to notice the unexpected event. In contrast to that study, the participants of our three experiments were all team sports players. The results of Experiments 1 and 2 showed that football players were much more likely to detect the unexpected object than the participants in the original study by Simons and Chabris [3] (Experiment 1: noticers, 73\%, non-noticers, $27 \%$; Experiment 2: noticers, $74 \%$, non-noticers, $26 \%$ ). This can be explained by some previous studies that have evidenced an advantage that team sports players have over individual athletes or non-athletes regarding their perceptual and attentional skills $[13,14]$.

Experiment 1 showed no significant differences between inattentional blindness rates in amateur and expert football players even though the descriptive data presented in Table 1 demonstrate slight differences (experts' noticing rate: 77\%, amateurs' noticing rate: $69 \%$ ). One reason for the non-significant finding may be a too similar expertise level of the participants in Experiment 1. Therefore, it would be advisable for future research to compare non-football athletes with footballers playing in various leagues. Memmert [5] described an expertise effect concerning inattentional blindness after showing that basketball players are able to see the unexpected object in a basketball-specific video more often than non-basketball players (61\% vs. 37\%). According to Memmert [15], experts in team sports pay discernably more attention to unexpected events than novices do. They also require less attentional resources for their automated actions, like trapping the ball, calculating of the ball's trajectory, observing the opponents' movements. While it was previously assumed that inattentional blindness can, amongst other factors, be influenced by the sport-specificity of the task [16], the results of Experiments 1 and 2 suggest that, not only a task's sport-specificity, but also the nature of the sport (in our experiment, using subjects from another ball-sport) in general seems to have an impact on whether an unexpected object is perceived or not. Furley et al. [4] allude to the fact that inattentional blindness could have varyingly strong impacts on players on different positions in basketball, handball, or other sports. We confirmed this assumption with the current research.

The task which was used in the first two experiments is a general, well-established inattentional blindness task. Although, the participants in Experiments 1 and 2 were required to count the number of times the basketball was passed between the two teams, this task can be considered neither sport-specific, nor relevant to the actual sporting task. This is so because in order to solve the task, it did not matter in the end whether the unexpected object, in this case the gorilla, was detected or not. In Experiment 3, however, the detection of the unexpected object, in this case the unmarked teammate, could decide the outcome of the match. In this new inattentional blindness task, participants had to make a football-specific tactical decision and, thus, it can be considered a more ecologically valid task.

To improve the athletes' tactical abilities in sports, such training of relevant and likely game situations, therefore, seems to be much more important than training with the perception of some irrelevant and unlikely stimuli during the game. As the study by Furley et al. [4] suggests, the rationale for choosing a functional, sport-specific, attentiondemanding task was to improve the ecological validity of the inattentional blindness paradigm. Although, inattentional blindness has been found to be a very robust finding in the laboratory, there are only a few studies that have examined this phenomenon in ecologically valid settings $[17,18]$. While the approach implemented in the current study already emphasizes the practical relevance of inattentional blindness in the field of team 
sports, the investigation of a combination of sport-relevant settings in the field, remains a task for future research.

Across all three experiments, the findings support a position-specific advantage regarding inattentional blindness for more offensive players compared to more defensive players. As the offensive players usually spend most of the playing time in the central parts of the field, they need to absorb information from all around them, requiring a continuous 360-degree visual scanning. In general, the development of modern sports is progressing steadily in a way that the specialization of athletes and thus, the concentration on specific tasks and positions, keeps becoming increasingly important. In this context, it can be asked, in what ways do wingers and center-forwards differ from each other. In the current study, at least in Experiments 2 and 3, the positions of goalkeepers, defenders, midfielders, and strikers were differentiated. Future research should consider the exact positions of the players on the pitch.

Over the last few years, tactical formations in football have increasingly featured some common formations, like the 4-3-3 formation, in which the three attacking players are regarded as strikers, yet they actually assume different tasks and playing positions. In the current study, for the interpretation of the results from the different playing positions, wingers were considered as midfielders. Depending on the tactical formation though, wingers can also be placed more centrally in front of the goal, in which case, they would rather be considered as strikers due to their tactical tasks on the pitch. Furthermore, differences between the offensive and defensive midfielders, as well as between centerbacks and wingbacks should be investigated. However, in order to do that, a larger sample size would be required for future studies.

A series of studies has shown that the visual focus of attention-as a part of the visual field within which several stimuli can be consciously perceived-is spatially limited (for a review [19]). Therefore, it is possible that unexpected objects lie outside of the focus of attention and, consequently, cannot be consciously perceived. Even though, athletes, especially team athletes from fast-paced team and racket sports, often have greater attentional windows than individual athletes or non-athletes $[13,14]$, it can be assumed that a non-conscious perception of unexpected objects in the outer periphery can be attributed less to inattentional blindness and more to the spatial limitations of attention. Different approaches to the training of athletes' visual spatial attention skills already exist to a certain extent [20]. However, future research should still test whether athletes' cognitive skills can be trained specifically to detect unexpected objects, such as teammates or opponents, more frequently and sooner.

In a recently study [21], it was shown that it is not the distance from gaze fixation, but the spatial distribution of attentional resources that primarily determines detection rates of unexpected objects in the visual periphery [22]. The authors found that inattentional blindness critically depends on the breadth of the attentional focus. This means that the space near gaze fixation gets significantly less attentional resources compared to more peripheral spatial locations, when the primary task demands attention to multiple peripheral objects. Based on these findings, future studies should not only investigate whether people perceive unexpected objects, but also whether there are differences based on where these objects are presented within their perceptual field and attentional focus.

With regard to laboratory studies, the use of a more representative viewing perspective should be considered, for example, by presenting unexpected objects not only on a flat screen but possibly also on a curved screen $[23,24]$. As curved screens distort the image less than flat screens, attention can be directed across larger visual angles on curved screens compared to flat screens [25]. Curved screens offer many other advantages over flat screens while demonstrating game situations or other real-life situations too, for example in a more realistic way while observing a road traffic scenario.

There are some more limitations of the current study and considerations for future research that need to be acknowledged. While in the first two experiments, the unexpected object, i.e., the gorilla, entered the video from the right side, in the third experiment, the 
unexpected object, i.e., the teammate, entered the video from the left side of the screen. As there might be asymmetrical differences in the participants' attentional focus or visual field [26], future studies should mirror the videos and the situations in order to investigate any field location-specific differences. Moreover, Hüttermann and Memmert [27] showed that physical load affects inattentional blindness. In contrast to high physical load and a state of rest, moderate physical exercise (i.e., $60 \%$ of heart rate frequency) has a positive impact on inattentional blindness, given that people under moderate physical exercise more frequently notice an unexpected object. Future studies in the field of inattentional blindness in sports should be conducted under conditions resembling those of the actual sport as closely as possible, i.e., among others, under the physical loads typical for the respective sports [28].

\section{Conclusions}

Using a standard inattentional blindness task developed by Simons and Chabris [3], Experiments 1 and 2 showed that inattentional blindness effects were less prevalent amongst football players playing in offensive positions (strikers) than amongst players playing in defensive positions (defenders). Finally, using a football-specific version of the task, Experiment 3 confirmed that these findings may transfer to more sport-specific settings in which the unexpected object (i.e., an open/undefended teammate entering the scene) is relevant to the main task objective - in this case, tactical decision making.

Author Contributions: Conceptualization, S.K. and J.N.; methodology, S.K. and J.N.; validation, S.K. and J.N.; formal analysis, S.K. and J.N.; investigation, S.K. and J.N.; resources, S.K. and J.N.; data curation, S.K. and J.N.; writing-original draft preparation, S.K.; writing-review and editing, S.K. and J.N.; visualization, S.K.; supervision, S.K.; project administration, S.K. Both authors have read and agreed to the published version of the manuscript.

Funding: This research received no external funding.

Institutional Review Board Statement: The study was conducted according to the guidelines of the Declaration of Helsinki and approved by the ethics committee of the German Sport University Cologne (number 094/21).

Informed Consent Statement: Informed consent was obtained from all subjects involved in the study.

Data Availability Statement: The data and materials are available on request to the first author.

Conflicts of Interest: The authors declare no conflict of interest.

\section{References}

1. Mack, A.; Rock, I. Inattentional Blindness; MIT Press: Cambridge, MA, USA, 1998; pp. 1-26.

2. Most, S.B.; Scholl, B.J.; Clifford, E.R.; Simons, D.J. What you see is what you set: Sustained inattentional blindness and the capture of awareness. Psychol. Rev. 2005, 112, 217-242. [CrossRef] [PubMed]

3. Simons, D.J.; Chabris, C.F. Gorillas in our midst: Sustained inattentional blindness for dynamic events. Perception 1999, 28, 1059-1074. [CrossRef]

4. Furley, P.; Memmert, D. The dark side of visual awareness in sport: Inattentional blindness in a real-world basketball task. Atten. Percept. Psychophys. 2010, 72, 1327-1337. [CrossRef]

5. Memmert, D. The effects of eye movements, age, and expertise on inattentional blindness. Conscious. Cogn. 2006, 15, 620-627. [CrossRef]

6. Broadbent, D.E. Perception and Communication; Pergamon Press: New York, NY, USA, 1958. [CrossRef]

7. Knudsen, E.I. Fundamental components of attention. Annu. Rev. Neurosci. 2007, 30, 57-78. [CrossRef]

8. Memmert, D.; Simons, D.J.; Grimme, T. The relationship between visual attention and expertise in sports. Psychol. Sport Exerc. 2009, 10, 146-151. [CrossRef]

9. Memmert, D.; Furley, P. "I spy with my little eye!"-Breadth of attention, inattentional blindness, and tactical decision making in team sports. J. Sport Exerc. Psychol. 2007, 29, 365-381. [CrossRef] [PubMed]

10. Hughes, M.; Caudrelier, T.; James, N.; Redwood-Brown, A.; Donnelly, I.; Kirkbride, A.; Duschesne, C. Moneyball and soccer-An analysis of the key performance indicators of elite male soccer players by position. J. Hum. Sport 2012, 7, 402-412. [CrossRef]

11. Williams, A.M.; Reilly, T. Talent identification and development in soccer. J. Sports Sci. 2000, 18, 657-667. [CrossRef]

12. Pocock, C.; Dicks, M.; Thelwell, R.C.; Chapman, M.; Barker, J.B. Using an imagery intervention to train visual exploratory activity in elite academy football players. J. Appl. Sport Psychol. 2017, 31, 218-234. [CrossRef] 
13. Hüttermann, S.; Memmert, D.; Simons, D.J.; Bock, O. Fixation strategy influences the ability to focus attention on two spatially separate objects. PLoS ONE 2013, 8, e65673. [CrossRef]

14. Hüttermann, S.; Memmert, D.; Simons, D.J. The size and shape of the attentional "spotlight" varies with differences in sports expertise. J. Exp. Psychol. Appl. 2014, 20, 147-157. [CrossRef] [PubMed]

15. Memmert, D. Inattentional blindness to unexpected events in 8-15-year-olds. Cogn. Dev. 2014, 32, 103-109. [CrossRef]

16. Memmert, D. Pay attention! A review of attentional expertise in sport. Int. Rev. Sport Exerc. Psychol. 2009, 2, 119-138. [CrossRef]

17. Most, S.B.; Astur, R.S. Feature-based attentional set as a cause of traffic accidents. Vis. Cogn. 2007, 15, 125-132. [CrossRef]

18. Strayer, D.L.; Drews, F.A.; Johnston, W.A. Cell phone-induced failures of visual attention during simulated driving. J. Exp. Psychol. Appl. 2003, 9, 23-32. [CrossRef] [PubMed]

19. Hüttermann, S.; Memmert, D. The attention window: A narrative review of limitations and opportunities influencing the focus of attention. Res. Q. Exerc. Sport 2017, 88, 169-183. [CrossRef]

20. Hüttermann, S.; Memmert, D. Effects of lab- and field-based attentional training on athletes' attention-window. Psychol. Sport Exerc. 2018, 38, 17-27. [CrossRef]

21. Kreitz, C.; Hüttermann, S.; Memmert, D. Distance is relative: Inattentional blindness critically depends on the breadth of the attentional focus. Conscious. Cogn. 2020, 78, 102878. [CrossRef]

22. Newby, E.A.; Rock, I. Inattentional blindness as a function of proximity to the focus of attention. Perception 1998, 27, 1025-1040. [CrossRef]

23. Hüttermann, S.; Ford, P.R.; Williams, A.M.; Varga, M.; Smeeton, N.J. Attention, perception, and action in a simulated decisionmaking task. J. Sport Exerc. Psychol. 2019, 41, 230-241. [CrossRef] [PubMed]

24. Hüttermann, S.; Smeeton, N.J.; Ford, P.R.; Williams, A.M. Color perception and attentional load in dynamic, time-constrained environments. Front. Psychol. 2019, 9, 2614. [CrossRef]

25. Klatt, S.; Smeeton, N.J. Immersive screens change attention width but not perception or decision-making performance in natural and basic tasks. Appl. Ergon. 2020, 82, 102961. [CrossRef]

26. Klatt, S.; Ford, P.R.; Smeeton, N.J. Attentional and perceptual asymmetries in an immersive decision-making task. Atten. Percept. Psychophys. 2020, 82, 1847-1857. [CrossRef] [PubMed]

27. Hüttermann, S.; Memmert, D. Moderate movement, more vision: Effects of physical exercise on inattentional blindness. Perception 2012, 41, 963-975. [CrossRef]

28. Klatt, S.; Smeeton, N.J. Attentional and perceptual capabilities are affected by high physical load in a simulated soccer decisionmaking task. Sport Exerc. Perform. Psychol. 2020, 10, 205-216. [CrossRef] 